\title{
Site and mechanism of leptin action in a rodent form of congenital lipodystrophy
}

\author{
Esra Asilmaz, ${ }^{1}$ Paul Cohen, ${ }^{1}$ Makoto Miyazaki, ${ }^{2}$ Pawel Dobrzyn, ${ }^{2}$ Kohjiro Ueki, ${ }^{3}$ \\ Gulnorakhon Fayzikhodjaeva, ${ }^{1}$ Alexander A. Soukas, ${ }^{1}$ C. Ronald Kahn, ${ }^{3}$ \\ James M. Ntambi, ${ }^{2,4}$ Nicholas D. Socci, ${ }^{5,6}$ and Jeffrey M. Friedman ${ }^{1,7}$ \\ ${ }^{1}$ Laboratory of Molecular Genetics, The Rockefeller University, New York, New York, USA \\ ${ }^{2}$ Department of Biochemistry, University of Wisconsin, Madison, Wisconsin, USA \\ ${ }^{3}$ Joslin Diabetes Center and Department of Medicine, Harvard Medical School, Boston, Massachusetts, USA \\ ${ }^{4}$ Department of Nutritional Sciences, University of Wisconsin, Madison, Wisconsin, USA \\ ${ }^{5}$ Department of Pathology, and \\ ${ }^{6}$ Seaver Foundation Center for Bioinformatics, Albert Einstein College of Medicine, Bronx, New York, USA \\ ${ }^{7}$ Howard Hughes Medical Institute, The Rockefeller University, New York, New York, USA
}

\begin{abstract}
Lipodystrophy is characterized by the complete or partial absence of adipose tissue, insulin resistance, hepatic steatosis, and leptin deficiency. Here, we show that low-dose central leptin corrects the insulin resistance and fatty liver of lipodystrophic aP2-nSREBP-1c mice, while the same dose given peripherally does not. Central leptin also repressed stearoyl-CoA desaturase-1 (SCD-1) RNA and enzymatic activity, which were increased in livers of lipodystrophic mice. aP2-nSREBP-1c mice homozygous for an SCD-1 deletion had markedly reduced hepatic steatosis, increased saturated fatty acids, decreased acetyl-CoA carboxylase activity, and decreased malonyl-CoA levels in the liver. Despite the reduction in hepatic steatosis, these mice remained diabetic. A leptin dose-response curve showed that subcutaneous leptin improved hyperglycemia and hyperinsulinemia in aP2-nSREBP-1c mice at doses that did not substantially alter hepatic steatosis or hepatic SCD enzymatic activity. Leptin treatment at this dose improved insulin-stimulated insulin receptor and insulin receptor substrate 2 (IRS-2) phosphorylation, IRS-2-associated PI3K activity, and Akt activity in liver. Together, these data suggest that CNS-mediated repression of SCD-1 contributes to leptin's antisteatotic actions. Intracerebroventricular leptin improves glucose homeostasis by improving insulin signal transduction in liver, but in this case the effect appears to be independent of SCD-1.
\end{abstract}

J. Clin. Invest. 113:414-424 (2004). doi:10.1172/JCI200419511.

\section{Introduction}

Leptin is an adipocyte hormone that modulates energy balance, metabolism, the hypothalamic-pituitary axis, and immune function $(1,2)$. Leptin also enhances insulin action, although the underlying mechanism has not been fully elucidated (3-5). Recently, leptin was found to be highly effective for treating the diabetes, insulin resistance, and hepatic steatosis associated with human lipodystrophy $(6,7)$. Leptin has similar effects in lipodystrophic rodents, most notably in aP2nSREBP-1c transgenic mice. These animals express a

Received for publication July 17, 2003, and accepted in revised form December 2, 2003.

Address correspondence to: Jeffrey M. Friedman, Howard Hughes Medical Institute, The Rockefeller University, 1230 York Avenue, Box 305, New York, New York 10021, USA. Phone: (212) 327-8800; Fax: (212) 327-7420;

E-mail: friedj@mail.rockefeller.edu.

Conflict of interest: J.M. Friedman will receive a portion of the royalties from Amgen Inc. (Thousand Oaks, California, USA) when and if leptin becomes a commercial product. None of the other authors have any financial interest in leptin or the results published in this report.

Nonstandard abbreviations used: stearoyl-CoA desaturase- 1 (SCD-1); acetyl-CoA carboxylase (ACC); insulin receptor substrate (IRS). truncated, constitutively active form of the SREBP-1c transcription factor under the control of the adiposespecific aP2 promoter and develop lipodystrophy with very low plasma leptin levels, hyperphagia, massive fat accumulation in peripheral tissues, hyperglycemia, and hyperinsulinemia (8). In these mice, peripheral leptin administration corrects the metabolic abnormalities associated with lipodystrophy (9). In A-ZIP/F1 mice, which have another form of rodent lipoatrophy, leptin also corrects insulin resistance and hepatic steatosis, albeit at higher doses $(10,11)$. In these animals, fat transplants from WT, but not $o b / o b$, mice also ameliorate this condition, confirming that leptin is necessary for the antidiabetic effects of fat transplants $(12,13)$. Recently, leptin was also shown to reverse the hyperglycemia and hyperinsulinemia associated with Irs1 $1^{-/} ;$Irs3 $3^{-/}$lipoatrophic mice (14).

Leptin has been reported to act directly on a number of tissues, including brain, skeletal muscle, heart, and pancreatic $\beta$ cells (15-18). However, at present, neither the site nor the mechanism by which leptin corrects the abnormalities associated with lipodystrophy has been established. Here we show that low-dose icv leptin corrected the metabolic abnormalities associated with lipodystrophy. icv leptin also repressed stearoyl-CoA 
desaturase-1 (SCD-1) in the livers of lipodystrophic animals. The contribution of SCD-1 to the diabetic and steatotic phenotype of lipodystrophic mice was assessed in crosses to SCD-1-deficient (asebia) mice. These studies showed that leptin acts via the CNS to reduce SCD-1 RNA and activity levels in liver, thereby improving hepatic steatosis. Further studies suggest that leptin improves diabetes in lipodystrophic mice via an insulin-dependent pathway that appears to be independent of its effects on SCD-1 and steatosis. These data identify a potential site and mechanism by which leptin action reduces steatosis and also have important implications for leptin's insulin-sensitizing effects.

\section{Methods}

Mouse breeding and maintenance. aP2-nSREBP-1c mice were purchased from The Jackson Laboratory (Bar Harbor, Maine, USA). aP2-nSREBP-1c males $(\mathrm{C} 57 \mathrm{BL} / 6 \mathrm{~J} \times \mathrm{SJL}$ background) were crossed to C57BL/6J females. aP2nSREBP-1c males and littermate controls generated from this cross were used in the following studies. Asebia $\left(a b^{J} / a b^{J}\right)$ mice were purchased from The Jackson Laboratory. We crossed $a b^{J} / a b^{J}$ mice (background information is available at http://www.informatics.jax.org/external/ festing/mouse/docs/ABJ.shtml) to aP2-nSREBP-1c mice to generate $a b J /+; \mathrm{aP2}$-nSREBP-1c males; these males were then crossed with $a b^{J} /+$ females to generate $a b J / a b J$;aP2nSREBP-1c mice and littermate controls. Genotypes were determined by genomic PCR and Southern blotting. All animals were housed on a 12-hour light/dark cycle at $23^{\circ} \mathrm{C}$ with free access to water and food. All procedures were in accordance with the guidelines of The Rockefeller University Laboratory Animal Research Center.

Metabolic assays and procedures. Upon sacrificing the mice, blood was collected in EDTA containing tubes, and plasma was obtained following centrifugation of blood. We measured plasma leptin and insulin levels using mouse ELISA kits (R\&D Systems Inc., Minneapolis, Minnesota, USA; and ALPCO Diagnostics, Windham, New Hampshire, USA, respectively). We determined plasma glucose, triglyceride, and cholesterol levels using Glucose Trinder reagent, Infinity Triglycerides reagent, and Infinity Cholesterol reagent, respectively (Sigma-Aldrich, St. Louis, Missouri, USA). We measured liver triglyceride levels as previously described (19). Histology was performed on livers fixed in $10 \%$ formalin and stained with H\&E.

Intracerebroventricular leptin treatment. Mice were studied between 14 and 18 weeks of age. Two weeks before leptin treatment, mice were individually caged. Baseline weight and food intake were measured every other day in the mid-light cycle. At the beginning of treatment, mice were divided into two weight-matched groups. One group was treated with $12 \mathrm{ng} / \mathrm{h}$ of recombinant mouse leptin (Amgen Inc., Thousand Oaks, California, USA) and the other was treated with PBS for 12 days. Mice were anesthetized with ketamine and xylazine, and a cannula connected to an ALZET miniosmotic pump (ALZA Corp., Palo Alto, California,
USA) was placed into the third ventricle as previously described (20). During the treatment, food intake and body weight were recorded daily, and on day 12 , mice were sacrificed during the mid-light cycle.

Subcutaneous leptin treatment. aP2-nSREBP-1c mice were treated with $12 \mathrm{ng} / \mathrm{h}, 25 \mathrm{ng} / \mathrm{h}, 50 \mathrm{ng} / \mathrm{h}, 100 \mathrm{ng} / \mathrm{h}$, and $200 \mathrm{ng} / \mathrm{h}$ of recombinant mouse leptin or PBS for 12 days using subcutaneously placed ALZET miniosmotic pumps, as previously described (20). Food intake and weight were monitored as described above.

Microarrays. RNA isolated from four individual liver samples was pooled, labeled, and hybridized once to Affymetrix Murine Genome U74Av2 chips according to Affymetrix protocols (Affymetrix Inc., Santa Clara, California, USA). In specific cases, Affymetrix results were reconfirmed using TaqMan real-time PCR assay. Initial analysis and comparisons were performed using a foldchange cutoff of 1.5 , a change $P$ value of less than 0.0025 , and a detection $P$ value of 0.05 in the experiment or base line depending on the sign of the fold change.

Cluster and correlation analysis. Cluster analysis was performed using standard hierarchical clustering with the average-linkage method. The distance measure was $(1-p) / 2$, where $p$ is the Pearson correlation function (see Supplemental Methods for a full description of the correlation analysis; http://www.jci.org/cgi/content/full/ 113/3/414/DC1).

SCD enzymatic activity. Conversion of $\left[1-{ }^{14} \mathrm{C}\right]$ stearoylCoA to $\left[1-{ }^{14} \mathrm{C}\right]$ oleate was used to measure SCD enzyme activity from individual liver extracts as previously described (19).

TaqMan. SCD-1 mRNA levels were quantitated using TaqMan real-time PCR from individual livers with probes and primers designed for SCD-1. SCD-1 RNA levels were measured in duplicate in aP2-nSREBP-1c mice, WT littermates, and aP2-nSREBP-1c mice treated with icv leptin, icv PBS, and several doses of peripheral leptin. A cyclophilin probe and primers were used to quantify cyclophilin mRNA levels as a control for each sample.

Fatty acid analysis. Total lipids were extracted from tissues according to the method of Bligh and Dyer as previously described (21). The fatty acids were quantitated by gas liquid chromatography as previously described (22). Pentadecanoic acid (Sigma-Aldrich) was added as an internal standard for the quantitation of fatty acids.

Extraction and measurement of acetyl-CoA carboxylase activity. Isolation of acetyl-CoA carboxylase (ACC) was performed as previously described (23). ACC activity in the $6 \%$ polyethylene glycol 8000 fraction was determined using the $\left[{ }^{14} \mathrm{C}\right]$ bicarbonate fixation assay (24).

Determination of malonyl-CoA content. Malonyl-CoA levels in liver were measured using highly purified fatty acid synthetase as previously described (25).

In vivo insulin stimulation and analysis of insulin-signaling proteins. Male aP2-nSREBP-1c mice were treated for 12 days with either $50 \mathrm{ng} / \mathrm{h}$ of subcutaneous leptin or PBS. On day 12 , mice were anesthetized with pentobarbital after an overnight fast, and injected with 5 units of regular human insulin (Lilly Research Laboratories, Indi- 
a
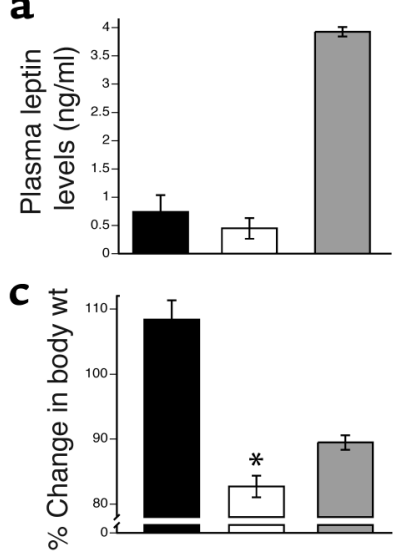

e

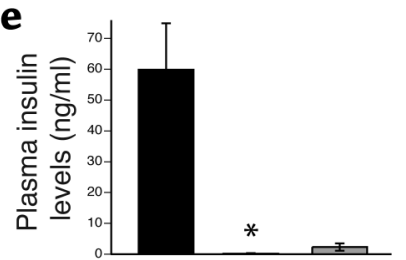

b
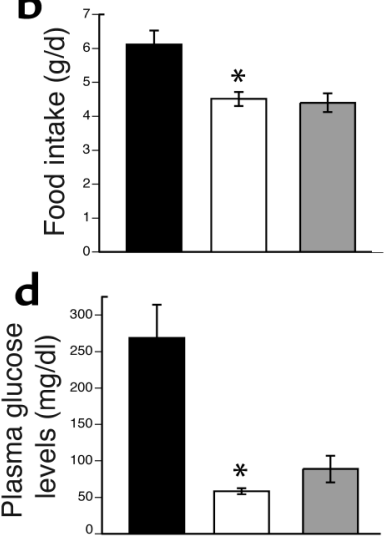

icv PBS

icv leptin (12 ng/h)

Subcutaneous leptin (200 ng/h)

Figure 1

Effects of central and peripheral leptin in rodent lipodystrophy. Several metabolic parameters in aP2-nSREBP-1c transgenic mice treated with icv PBS, icv leptin (12 ng/h), and subcutaneous leptin (200 $\mathrm{ng} / \mathrm{h}$ ) are shown. (a, d, and e) Plasma levels of leptin, glucose, and insulin, respectively. (b) Average daily food intake for the 12-day treatment. (c) Percentage change in body weight. One hundred percent change indicates the weight of the mice on the day of pump insertion. Error bars indicate the SE for four mice per group for each treatment. ${ }^{*} P<0.05$, icv leptin vs. icv PBS.

anapolis, Indiana, USA) into the inferior vena cava. Livers and muscles were excised after 5 minutes and freezeclamped in liquid nitrogen. Insulin-signaling molecules were analyzed as previously described (26).

PI $3 K$ assay and AKT kinase assay. Liver and muscle homogenates from the in vivo insulin stimulation were used to assay PI3K and AKT kinase activity as previously described (26).

Statistical analysis. All data are expressed as means \pm SE. An unpaired Student's $t$ test was used to determine significance.

\section{Results}

Intracerebroventricular leptin administration corrects the metabolic abnormalities associated with lipodystrophy. We administered recombinant murine leptin $(12 \mathrm{ng} / \mathrm{h}$ ) or PBS icv to aP2-nSREBP-1c mice for 12 days (20) (Figure 1). In separate studies, lipodystrophic animals were treated with a higher dose of subcutaneous leptin (200 $\mathrm{ng} / \mathrm{h}$ for 12 days) or PBS. This subcutaneous dose has previously been shown to fully correct the metabolic defects in lipodystrophic mice (9). Intracerebroventricular leptin $(12 \mathrm{ng} / \mathrm{h})$ did not change plasma leptin levels in lipodystrophic mice (Figure 1a). In animals treated with icv leptin, food intake was reduced by $26.2 \%$ (Figure 1b) and body weight was reduced by $17.3 \%$ (Fig-

ure 1c) relative to PBS-treated controls. This dose of icv leptin treatment markedly improved insulin sensitivity, as both plasma glucose and plasma insulin levels were significantly lowered (Figure 1, d and e). Finally, icv leptin treatment decreased liver triglyceride levels sevenfold (Figure $2 \mathrm{a}$ ) and reduced liver mass by $67.5 \%$ relative to PBS-treated controls (Figure $2 \mathrm{~b}$ ). Histological analysis confirmed that the icv leptin treatment corrected the fatty liver of aP2-nSREBP-1c mice (Figure 2, $\mathrm{c}$ and d). As an additional control, we treated a separate group of aP2-nSREBP-1c mice with $12 \mathrm{ng} / \mathrm{h}$ of peripheral leptin, the same dose used in the icv treatment. This dose had no effect on any of the parameters shown in Figures 1 and 2 (data not shown). In all cases, icv leptin was as potent as or more potent than a much higher dose of peripheral leptin in correcting the metabolic abnormalities associated with lipodystrophy. These data suggest that leptin's effects on insulin action, diabetes, and hepatic steatosis in lipodystrophy can be mediated exclusively via the CNS.

Several liver genes involved in lipid and glucose metabolism are similarly altered by icv and subcutaneous leptin. We next compared liver gene expression profiles in aP2-nSREBP$1 \mathrm{c}$ and WT mice with and without peripheral or central leptin treatment. mRNAs for several enzymes involved in fatty acid synthesis, glycolysis, and gluconeogenesis have been previously found to be differentially expressed in livers of aP2-nSREBP-1c mice and normalized by peripheral leptin treatment (27). We examined the expression profiles of a group of genes known to regulate lipid and glucose metabolism following either central or peripheral leptin administration (Table 1).
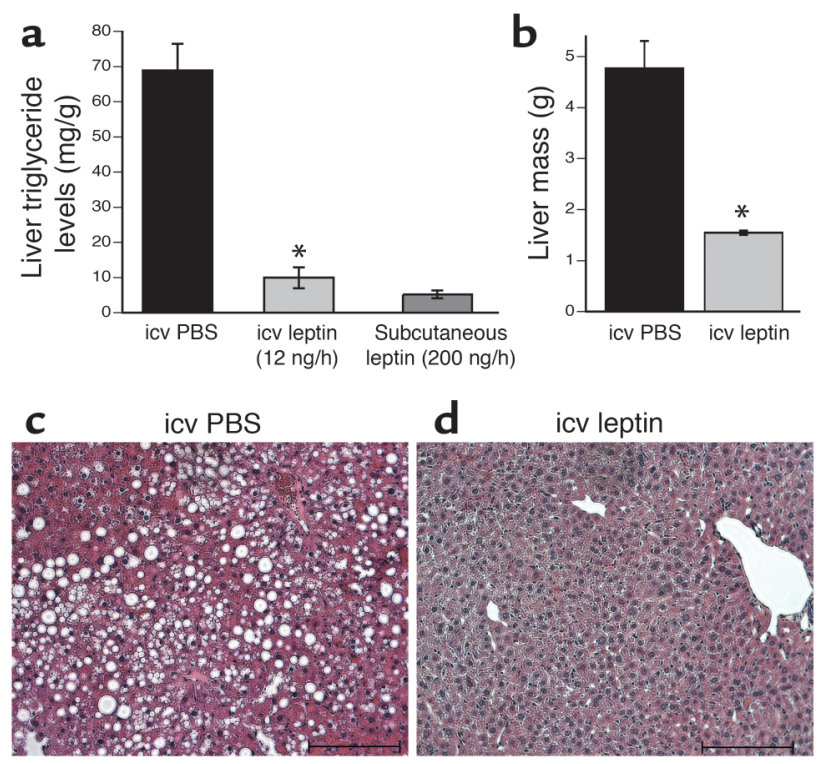

\section{Figure 2}

Correction of fatty liver with central leptin treatment. (a) Liver triglyceride content. (b) Liver mass in grams. Error bars indicate the SE for four mice per group for each treatment. ${ }^{*} P<0.05$, icv leptin vs. icv PBS. (c and d) Representative liver sections from mice treated with icv PBS and icv leptin. Original magnification, $\times 200$; scale bars: $100 \mu \mathrm{m}$. 
For each of these genes, an equivalent or greater response was evident after icv leptin treatment. For example, malic enzyme and fatty acid synthase, enzymes involved in fatty acid synthesis, were upregulated 3.0and 3.7-fold, respectively, in aP2-nSREBP-1c relative to WT liver. These two genes were downregulated 7.0- and 4.3-fold, respectively, after icv leptin administration versus 2.6-fold and twofold, respectively, after peripheral leptin treatment (relative to PBS-treated transgenic livers). In aP2-nSREBP-1c livers, pyruvate kinase, a glycolytic enzyme, and glucose-6-phosphatase, a gluconeogenic enzyme, were upregulated 3.0- and 3.3-fold, respectively, relative to WT livers. Intracerebroventricular leptin treatment downregulated these genes 7.0- and 4.3-fold, respectively, and peripheral leptin administration downregulated them 2.5 - and 1.5 -fold, respectively (relative to PBS-treated transgenic livers). Expression of these genes was normalized to WT levels following icv leptin treatment. Several other genes were similarly regulated by both central and peripheral leptin, with most genes more strongly regulated by icv than by peripheral leptin (see Supplemental Tables 1 and 2; http:// www.jci.org/cgi/content/full/113/3/414/DC1). Furthermore, many of the genes that were altered between lipodystrophic and WT livers were also differentially expressed in livers of $o b / o b$ mice compared with WT mice, indicating that the alterations in liver gene expression in aP2-nSREBP-1c mice resemble those of congenital leptin deficiency (19).

Global gene-expression profiles in livers of mice treated with $i c v$ and subcutaneous leptin are significantly correlated. In order to extend the analysis of gene expression beyond the comparison of a few key genes, we used standard hierarchical clustering to assess the similarity of central versus peripheral leptin treatment (Figure 3a). In the resulting dendrogram, the transcription profiles in liver after subcutaneous and icv leptin treatments clustered together, indicating that the gene expression pattern of icv leptin treatment was more similar to the $200-\mathrm{ng} / \mathrm{h}$ dose of peripheral leptin treatment than to any others tested.
In order to provide more robust quantitative information on the significance of the similarities, we developed a novel approach to determine the significance of the similarity (correlation) between the transcription profiles in liver following icv and subcutaneous leptin administration. We compared the global gene-expression profiles of icv and subcutaneous leptin treatment using two methods: (i) correlation analysis between genes that are similarly regulated in both experiments, in what is referred to as the intersection set, and (ii) correlation analysis among genes that are regulated in either or both experiments, in what is referred to as the union set (see Supplemental Note 1 for a more detailed description of this method; http://www.jci.org/cgi/content/full/113/3/414/DC1). A linear regression of the logarithms of the fold changes in the intersection set showed a slope of 0.6 of peripheral leptin vs. icv leptin and a correlation coefficient of 0.897 (Figure $3 b$ ). The slope of 0.6 indicated that, in general, icv leptin treatment had a greater effect than subcutaneous leptin administration (see Supplemental Note 2). In this analysis, in the union set, the correlation of icv versus subcutaneous leptin treatment was 0.738 (Figure 3b), with a calculated $P$ value of approximately 0.0014 . This correlation was one of the highest correlations observed among the 3,692 pairs of samples that were studied, indicating that the transcriptional responses to icv and subcutaneous leptin are highly similar (Figure 3d) (see Supplemental Note 3).

Transcription profiles in skeletal muscle. As muscle is the primary site of insulin-stimulated glucose disposal, we also analyzed gene-expression profiles in skeletal muscle of aP2-nSREBP-1c transgenic mice following $\mathrm{icv}$ and subcutaneous leptin administration. In contrast to the effects of leptin on gene expression in liver, gene expression in skeletal muscle was largely unchanged by central and peripheral leptin. The genes that were regulated by leptin included major urinary protein group 1 , acetylCoA dehydrogenase, dienoyl-CoA isomerase ECH1p, and fatty acid-binding protein 3 . Consistent with other findings, the correlation between central and peripher-

Table 1

Comparison of gene expression regulated by icv versus subcutaneous leptin in liver of aP2-nSREBP-1c transgenic mice

\begin{tabular}{|c|c|c|c|c|}
\hline \multirow[t]{2}{*}{ Accession number } & \multirow[t]{2}{*}{ Name } & \multirow[t]{2}{*}{ Function } & \multicolumn{2}{|c|}{ Fold change } \\
\hline & & & icv leptin & Subcutaneous leptin \\
\hline J02652 & Malic enzyme & Lipid metabolism & -6.96 & -2.64 \\
\hline D63764 & Pyruvate kinase & Glucose metabolism & -6.96 & -2.46 \\
\hline X13135 & Fatty acid synthase & Lipid metabolism & -4.29 & -2.00 \\
\hline U00445 & Glucose-6-phosphatase & Glucose metabolism & -4.29 & -1.52 \\
\hline AW122523 & L-chain fatty acyl elongase & Lipid metabolism & -6.06 & -3.25 \\
\hline U10374 & PPAR $\gamma$ & Transcription factor & -6.50 & -1.52 \\
\hline X85983 & Carnitine acetyltransferase & Lipid metabolism & -2.14 & -1.62 \\
\hline X58426 & Hepatic lipase & Lipid metabolism & 2.14 & 1.62 \\
\hline U95945 & HNF6 & Transcription factor & 3.03 & 2.83 \\
\hline X74938 & HNF3 $\gamma$ & Transcription factor & 1.74 & 2.14 \\
\hline AB033887 & Fatty acyl-CoA ligase & Lipid metabolism & 2.30 & 1.87 \\
\hline
\end{tabular}

The line space separates the genes downregulated by leptin treatment (above the line space) from the genes upregulated by leptin treatment (below the line space). 
a

\begin{tabular}{ccccccccc} 
Distance & & & \\
& 0.0 & 0.1 & 0.2 & 0.3 & 0.4 & 0.5 & 0.6 \\
\hline
\end{tabular}
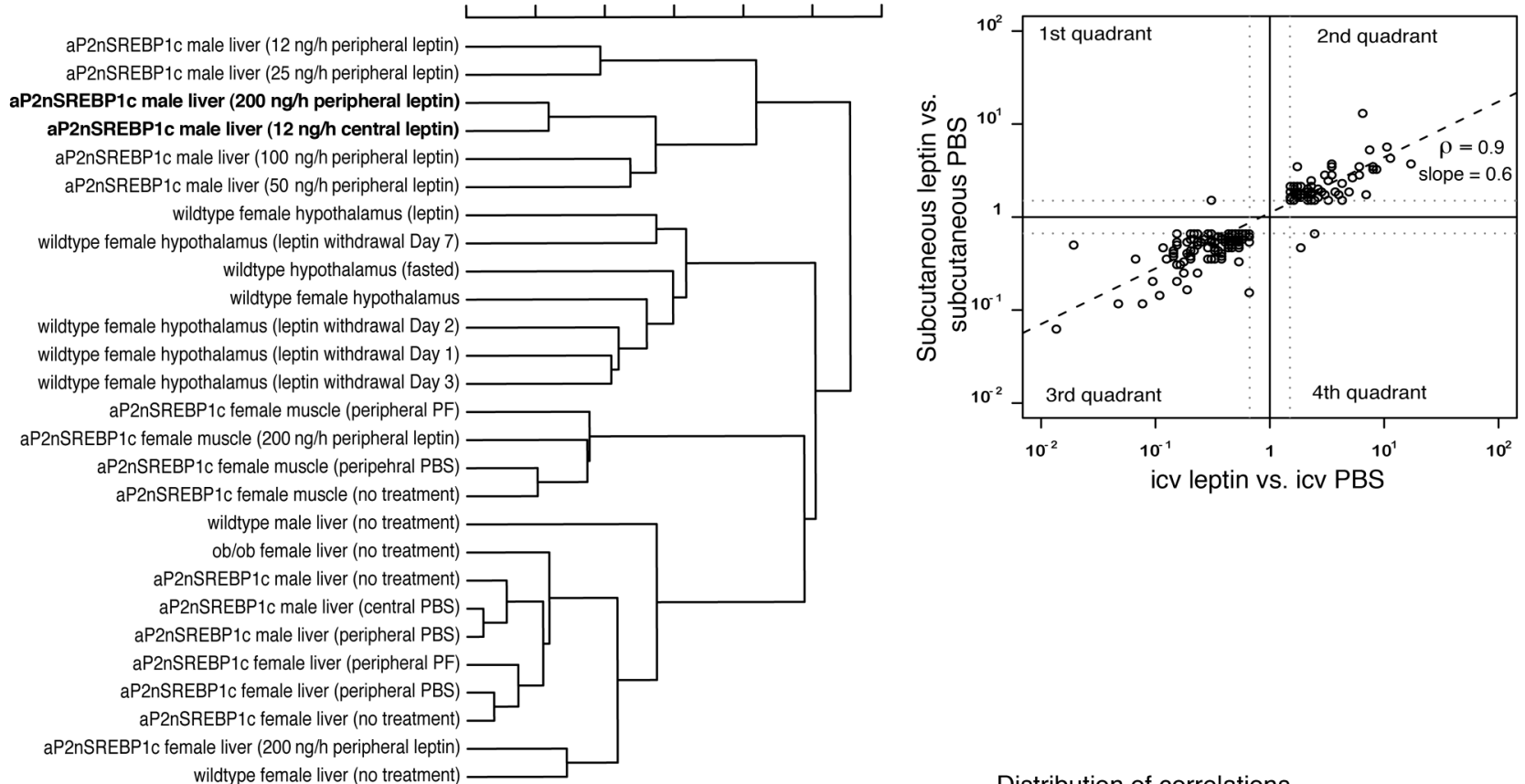

(notroting
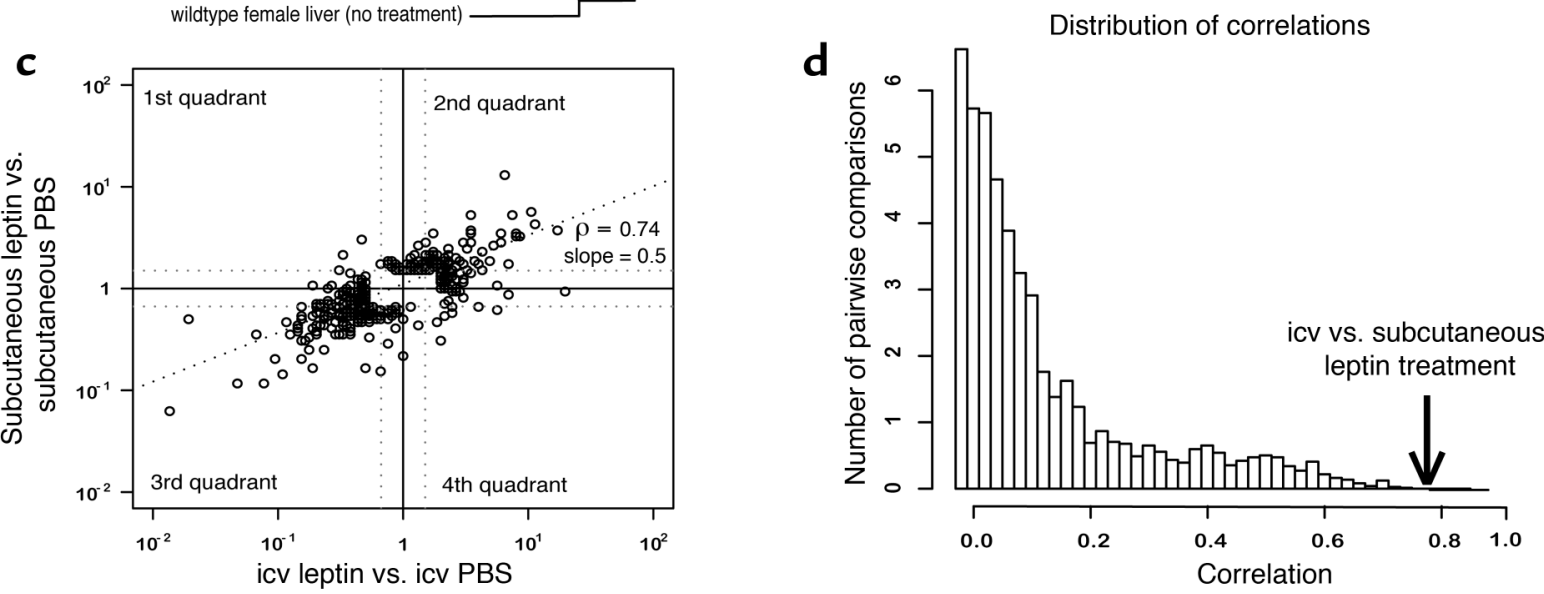

Figure 3

Computational analyses of the hepatic transcription profile after icv and subcutaneous leptin treatment. Cluster analysis, correlation analysis, and the distribution of correlations of liver gene expression from mice treated with icv leptin versus icv PBS and subcutaneous leptin versus subcutaneous PBS are shown. (a) Standard hierarchical clustering of 30 microarray experiments, including icv leptin and subcutaneous leptin treatments, show that the transcription profiles of icv and subcutaneous leptin are more similar to each other than to any other sample. (b) A pairwise comparison of icv and subcutaneous leptin gene expression is shown for genes regulated by both treatments (the intersection set). In the first quadrant, gene expression is increased in subcutaneous treatment and decreased in icv treatment; in the second quadrant, gene expression is increased in both treatments; in the third quadrant, gene expression is decreased in both treatments; and in the fourth quadrant, gene expression is decreased in subcutaneous treatment and increased in icv treatment. In almost all cases, gene expression is similarly regulated by both treatments. $\rho$ denotes the correlation value. (c) The logarithm of fold changes of subcutaneous leptin versus PBS and icv leptin versus PBS for genes regulated by either treatment (the union set) is shown. (d) The distribution of correlations of 3,962 pairwise comparisons from our database is shown. The arrow shows the correlation of the icv leptin versus PBS treatment and the subcutaneous leptin versus PBS treatment. This shows that gene expression after icv and subcutaneous leptin is more highly correlated than for the other comparisons $(P<0.002)$.

al leptin was relatively low (see Supplemental Figure 1; http://www.jci.org/cgi/content/full/113/3/414/DC1), suggesting that leptin might directly influence gene expression in muscle but not in liver (16).

SCD-1 in lipodystrophy. The microarray studies showed that the levels of hepatic SCD-1 RNA were elevated in lipodystrophic livers and reduced by both central and peripheral leptin. SCD-1 is a microsomal enzyme that catalyzes the synthesis of monounsaturated fatty acids from saturated fatty acids $(19,28,29)$. The mRNA level for SCD-1 was elevated 2.3-fold in the liver of aP2nSREBP-1c relative to WT mice, and its enzymatic activity was increased 3.8-fold. Intracerebroventricular leptin administration reduced SCD-1 mRNA levels 


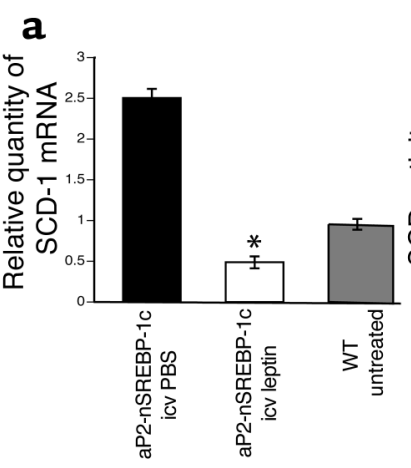

b

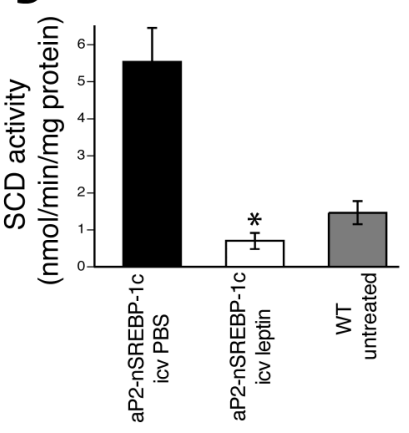

5.2-fold versus a 3.2-fold decrease for peripheral leptin treatment (Figure 4a). SCD enzyme activity was reduced $87.4 \%$ with icv leptin infusion and $68.2 \%$ with subcutaneous leptin administration relative to that in PBS-treated controls (Figure 4b). Both SCD-1 RNA and enzymatic activity were corrected to WT levels following either treatment.

To determine the extent to which high levels of SCD contribute to the fatty liver and insulin resistance of aP2-nSREBP-1c mice, we generated aP2-nSREBP-1c transgenic mice lacking SCD-1. The resulting $\mathrm{ab}^{\mathrm{J}} / \mathrm{ab}^{\mathrm{J}} ; \mathrm{aP} 2$-nSREBP-1c mice remained lipodystrophic, possessing virtually no white adipose tissue. However, in $\mathrm{ab}^{\mathrm{J}} / \mathrm{ab}^{\mathrm{J}}$;aP2-nSREBP-1c mice, the gross liver appearance was markedly improved (Figure 5a). Histological sections of the livers showed a marked reduction in the number of lipid droplets (Figure 5b), and liver triglyceride levels were significantly reduced (Figure 5c).

To further analyze the mechanism by which SCD deficiency improved hepatic steatosis, we measured hepatic lipid content, ACC activity, and malonyl-CoA levels. In aP2-nSREBP1c mice, the hepatic levels of 16:1 and 18:1 monounsaturated fats were increased compared with those in control mice. SCD-1 deficiency in $\mathrm{ab}^{\mathrm{J}} / \mathrm{ab}^{\mathrm{J}} ; \mathrm{aP} 2$-nSREBP-1c mice decreased the relative levels of monounsaturated fats to WT levels (Figure 5d). ACC activity and malonyl-CoA levels were significantly elevated in aP2-nSREBP-1c mice, and both were reduced to WT levels in $\mathrm{ab}^{\mathrm{J}} / \mathrm{ab}^{\mathrm{J}} ; \mathrm{aP} 2$-nSREBP-1c mice (Figure 5, e and $\mathrm{f}$ ). Reduction of the levels of ACC activity and malonyl-CoA acts to increase mitochondrial fatty acid import and fatty acid oxidation.

Despite the improved hepatic steatosis, the $\mathrm{ab}^{\mathrm{J}} / \mathrm{ab}^{\mathrm{J}} ; \mathrm{aP} 2$-nSREBP-1c animals were still hyperglycemic, with glucose levels as high as or higher than those of standard aP2-nSREBP-1c transgenic mice (Figure 5g). The $a b^{J} / a b^{J}$;aP2-nSREBP-1c mice had lower levels of insulin than aP2-nSREBP-1c transgenic mice (Figure 5h), which, coupled with the higher glucose levels, suggested that there was possibly $\beta$ cell failure. It has been previously suggested that accumulation of saturated fatty acids in a cell can lead to apoptosis (30). These data might suggest that lipid content and SCD-1 activity might also influence $\beta$ cell function or viability. Plasma triglycerides, cholesterol, and FFAs were

\section{Figure 4}

Regulation of SCD-1 by icv leptin. SCD-1 mRNA levels and enzyme activity are shown for aP2-nSREBP-1c transgenic mice treated with icv PBS, icv leptin, and WT littermate controls. (a) TaqMan real-time PCR of liver RNA samples using primers and probe specific for SCD-1. (b) Enzymatic activity measured in liver extracts. Error bars indicate the SE; $n=4$ for icv PBS and icv leptin, and $n=6$ for the WT group. ${ }^{*} P<0.05$, icv leptin vs. icv PBS.

unchanged in $a b^{J} / a b J$;aP2-nSREBP-1c mice versus aP2nSREBP-1c controls (data not shown).

Leptin improves insulin action independent of effects on bepatic steatosis and SCD activity. The results from studies of $a b^{J} / a^{J} ; a P 2-n S R E B P-1 c$ mice suggest that leptin's antidiabetic effects are independent of its ability to clear lipid in liver and other tissues. In order to further explore this possibility and the underlying mechanism, we generated a dose-response curve for subcutaneous leptin in aP2-nSREBP-1c mice. The objective of this study was to assess whether leptin's ability to improve diabetes was evident at the same dose as its ability to reduce steatosis, or at a different dose. We infused leptin at $12 \mathrm{ng} / \mathrm{h}, 25 \mathrm{ng} / \mathrm{h}, 50 \mathrm{ng} / \mathrm{h}$, and $100 \mathrm{ng} / \mathrm{h}$, with the highest dose being $200 \mathrm{ng} / \mathrm{h}$, a dose that has been previously shown to both improve diabetes and reduce steatosis (9). Liver triglyceride levels were corrected to WT levels at the 200-ng/h leptin dose, whereas the reductions were modest at the lower infusion rates (Figure 6a). Similarly, SCD-1 mRNA levels (see Supplemental Figure 2; http://www.jci.org/cgi/content/full/113/3/ 414/DC1) and SCD activity were corrected to WT levels only with the 200-ng/h leptin infusion (Figure 6b).

While SCD activity and liver triglyceride levels were normalized only at the highest dose, there was a significant reduction in both plasma glucose and plasma insulin levels at the 50-ng/h, 100-ng/h, and 200-ng/h leptin doses (Figure 6, c and d). Thus, leptin improves diabetes at doses that do not normalize hepatic steatosis or reduce SCD-1 activity to WT levels. This suggests the possibility that leptin's antidiabetic effects are independent of its ability to repress SCD- 1 and reduce steatosis. In principle, leptin could improve diabetes by increasing glucose uptake or decreasing hepatic glucose output independent of insulin or by improving insulin signal transduction. To distinguish between these possibilities, we studied the effects of insulin in aP2-nSREBP-1c mice after treatment with a dose of peripheral leptin $(50 \mathrm{ng} / \mathrm{h})$ that improves diabetes but does not correct steatosis or reduce SCD-1 activity to WT levels (Figure 6).

In the livers from lipodystrophic mice, there was a marked reduction in insulin-stimulated insulin receptor substrate 2 (IRS-2) phosphorylation and a decrease in both IRS-2-associated PI3K activity and Akt activity 
a

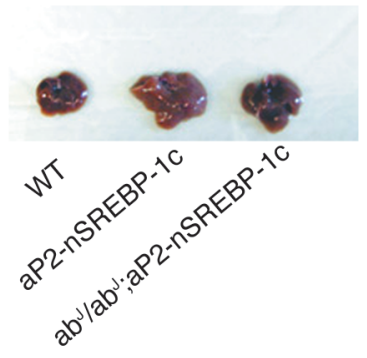

c

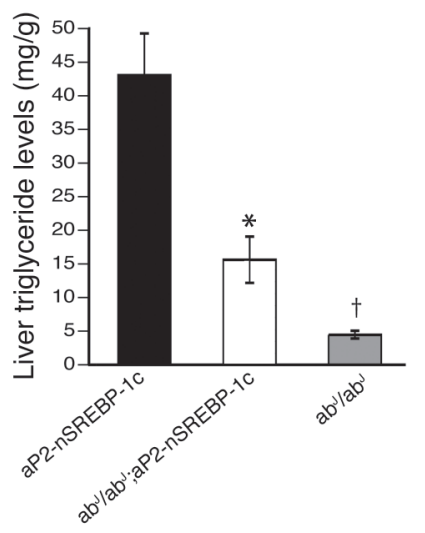

f

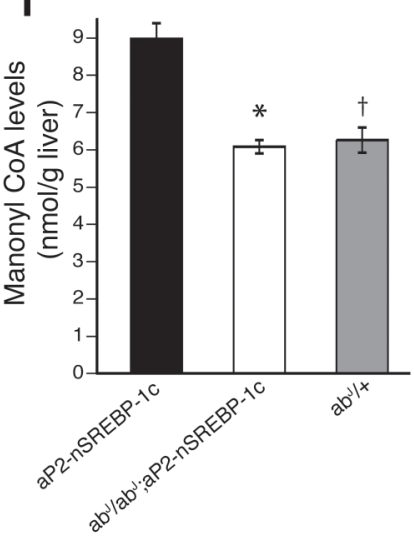

b

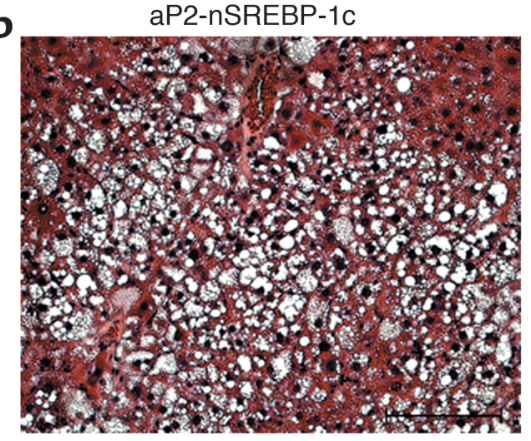

d

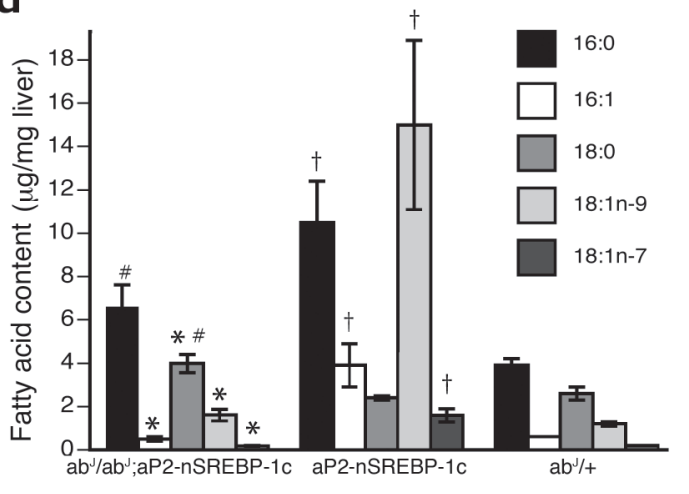

$a b^{J} / a b^{J} ; a P 2-n S R E B P-1 c$

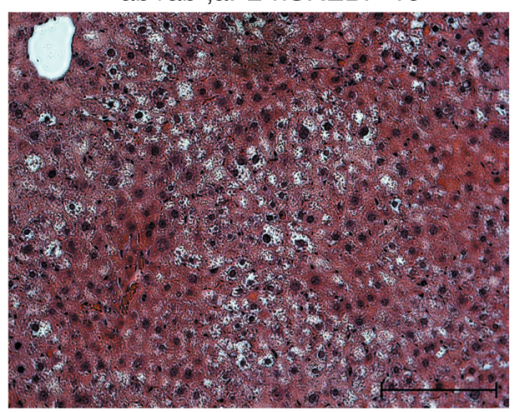

e

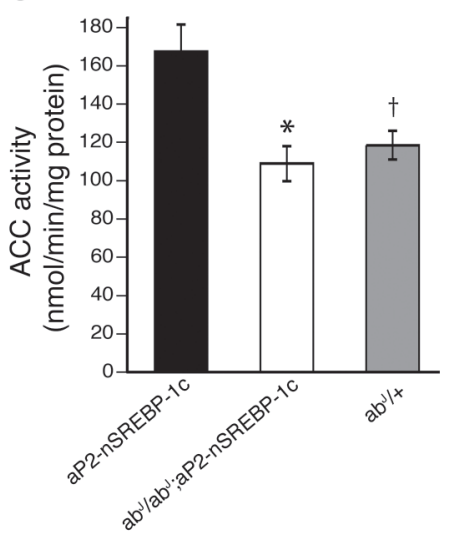

g

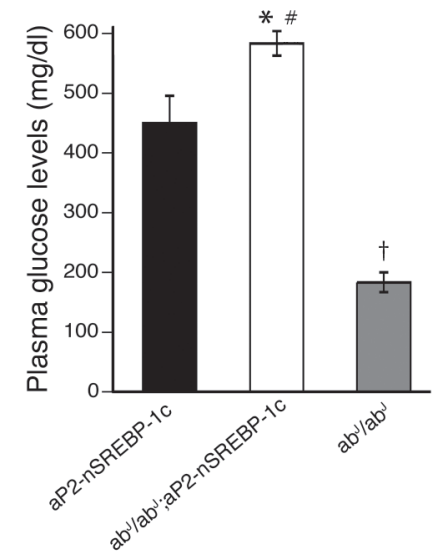

h

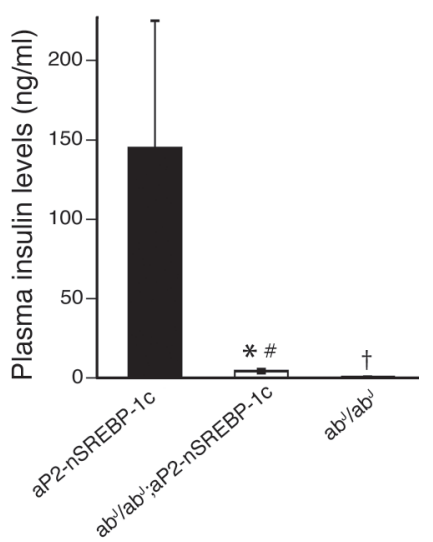

Figure 5

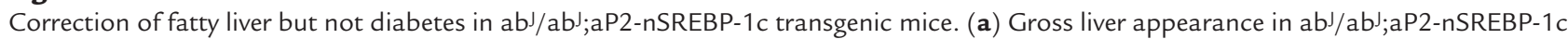
transgenic mice, aP2-nSREBP-1c transgenic mice, and WT mice. (b) Representative liver sections from aP2-nSREBP-1c and abj/abj; $\mathrm{aP}^{\mathrm{B}}$ nSREBP-1c mice. Original magnification, $\times 200$; scale bars: $100 \mu \mathrm{m}$. (c) Liver triglyceride levels. (d) Fatty acid content in liver. (e) ACC activity in liver. (f) Malonyl-CoA levels in liver. ( $\mathbf{g}$ and $\mathbf{h}$ ) Plasma glucose and plasma insulin levels, respectively. Error bars indicate the SE; $n=7$

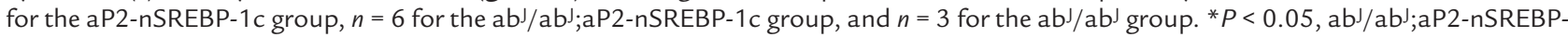

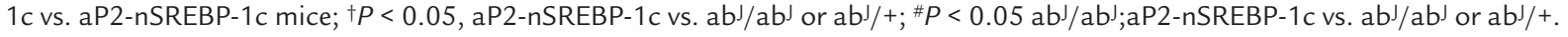

compared with those in the livers from WT animals (Figure 7, a-c). Leptin treatment $(50 \mathrm{ng} / \mathrm{h})$ normalized insulin-stimulated IRS-2 phosphorylation and IRS-2associated PI3K activity and Akt activity in livers of lipodystrophic mice (Figure 7, a-c). In skeletal muscle from the lipodystrophic mice, there was also a decrease in IRS-1-associated PI3K activity and Akt activity. However, in this tissue, leptin treatment did not fully correct the attenuated response to insulin (Figure 7, $\mathrm{d}$ and e).

\section{Discussion}

Leptin has potent antidiabetic and antisteatotic effects in human and rodent lipodystrophy $(6,9)$. Our findings strongly suggest that leptin's metabolic effects and its actions on liver gene expression in lipodystrophy are indirect via the CNS. This conclusion is consistent with data from icv treatment of leptin-deficient $o b / o b$ and WT mice (31). Furthermore, mice with a neuron-specific knockout of the leptin receptor are 

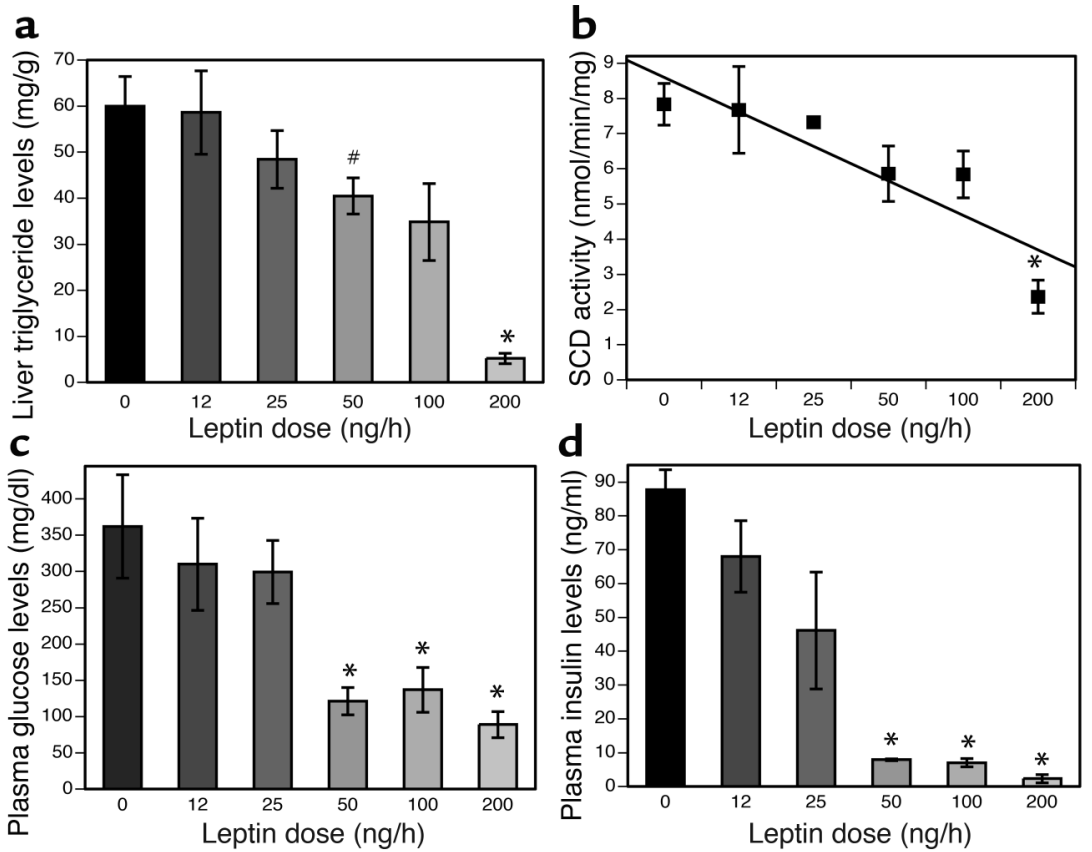

\section{Figure 6}

Dose-response curve for leptin treatment. Leptin corrects hyperinsulinemia and hyperglycemia at leptin doses that have no effect on SCD activity and gross liver appearance ( $50 \mathrm{ng} / \mathrm{h}$ and $100 \mathrm{ng} / \mathrm{h}$ ). (a) Liver triglyceride content. (b) SCD enzymatic activity measured in liver extracts of aP2-nSREBP-1c mice treated with several doses of subcutaneous leptin. (c and d) Plasma glucose and plasma insulin levels, respectively. Error bars indicate the SE; $n=3$ for $12 \mathrm{ng} / \mathrm{h}$ and $25 \mathrm{ng} / \mathrm{h}$ leptin, and $n=4$ for $0 \mathrm{ng} / \mathrm{h}, 50 \mathrm{ng} / \mathrm{h}, 100 \mathrm{ng} / \mathrm{h}$, and $200 \mathrm{ng} / \mathrm{h}$ leptin. ${ }^{*} P<0.005,200-\mathrm{ng} / \mathrm{h}$ leptin dose vs. 0 -ng/h dose. ${ }^{*} P<0.05,50$-ng/h leptin dose vs. 0-ng/h dose. obese and develop hepatic steatosis, while mice with a liver-specific knockout are not obese and do not develop hepatic steatosis (15). Our conclusion above is also consistent with previous studies showing that the CNS plays an important role in regulating glucose homeostasis (32). Several recent reports suggest that leptin can exert direct effects on peripheral tissues. Leptin increases fatty acid oxidation in skeletal muscle by activating AMP-activated protein kinase (AMPK), which in turn phosphorylates and inactivates ACC (16). Leptin has also been suggested to activate fatty acid oxidation in the heart independent of AMPK activation (17). In liver, leptin is suggested to increase fatty acid oxidation by a mechanism dependent on PPAR $\alpha$ (33). While our results do not exclude the possibility that direct actions of leptin on peripheral tissues such as muscle may contribute to its effects in lipodystrophy, these actions are not required for the metabolic improvement seen after leptin treatment, since the abnormalities in aP2-nSREBP-1c mice were corrected by central leptin administration at doses that have no effect on plasma leptin levels.

Recent data have suggested that leptin reduces adiposity and liver triglyceride content, in part by reducing SCD-1 mRNA and enzymatic activity $(19,34)$. Our data are consistent with the possibility that leptin's effects to correct hepatic steatosis in lipodystrophy are also mediated, at least in part, by inhibition of SCD-1. Thus SCD-1 deficiency markedly improves hepatic steatosis in lipodystrophic animals. In aP2-nSREBP-1c transgenic mice, both SCD-1 mRNA levels and enzymatic activity were increased relative to WT controls, and icv leptin treatment significantly reduced SCD-1 mRNA levels and enzymatic activity. This suggests that efferent signals from the CNS are capable of repressing this enzyme. It was previously shown that saturated fatty acyl-CoAs can inhibit ACC, an effect that would decrease cellular malonyl-CoA levels $(35,36)$. A decrease in malonyl-CoA would be expected to de-repress the activity of carnitine palmitoyltransferase 1 (CPT-1), the rate-limiting enzyme for the mitochondrial import and oxidation of fatty acids (37). The data reported here further suggest that repression of SCD-1 is associated with reduced levels of ACC enzymatic activity and decreased malonyl-CoA levels, effects that would in turn act to de-repress CPT- 1 and increase fatty acid import and $\beta$-oxidation in mitochondria. Other mechanisms might also contribute to the antisteatotic effects of a deficiency of this enzyme.

While the CNS pathways and efferent signals responsible for SCD-1 repression by leptin are unknown, some of leptin's effects might be mediated by repression of neuropeptide Y (NPY). Leptin is known to repress NPY gene expression in hypothalamus, and NPY infusions induce liver ACC activity as well as other lipogenic genes (38). SCD-1 gene expression was recently shown to be reduced in $\mathrm{MCH}^{-/-} ; \mathrm{ob} / \mathrm{ob}$ mice, suggesting that leptin's effects on SCD-1 expression may also be mediated by regulation of melanin-concentrating hormone $(\mathrm{MCH})$ in the lateral hypothalamus (39). Recently, icv MTII (a melanocortin receptor agonist) injections were shown to decrease SCD-1 expression, suggesting that leptin represses SCD-1 through melanocortin receptors (40).

While SCD-1 deficiency reduces hepatic steatosis in liver in lipodystrophic mice, these animals remain severely diabetic. This suggests that leptin's antidiabetic effects are not simply a result of its ability to reduce triglyceride levels in peripheral tissues. It is still possible, however, that other lipid moieties that modulate insulin sensitivity remain unchanged in the absence of SCD-1 (41). The residual diabetes of $a b^{J} / a b^{J} ; \mathrm{aP} 2-\mathrm{nSREBP}-1 \mathrm{c}$ mice is consistent with the 

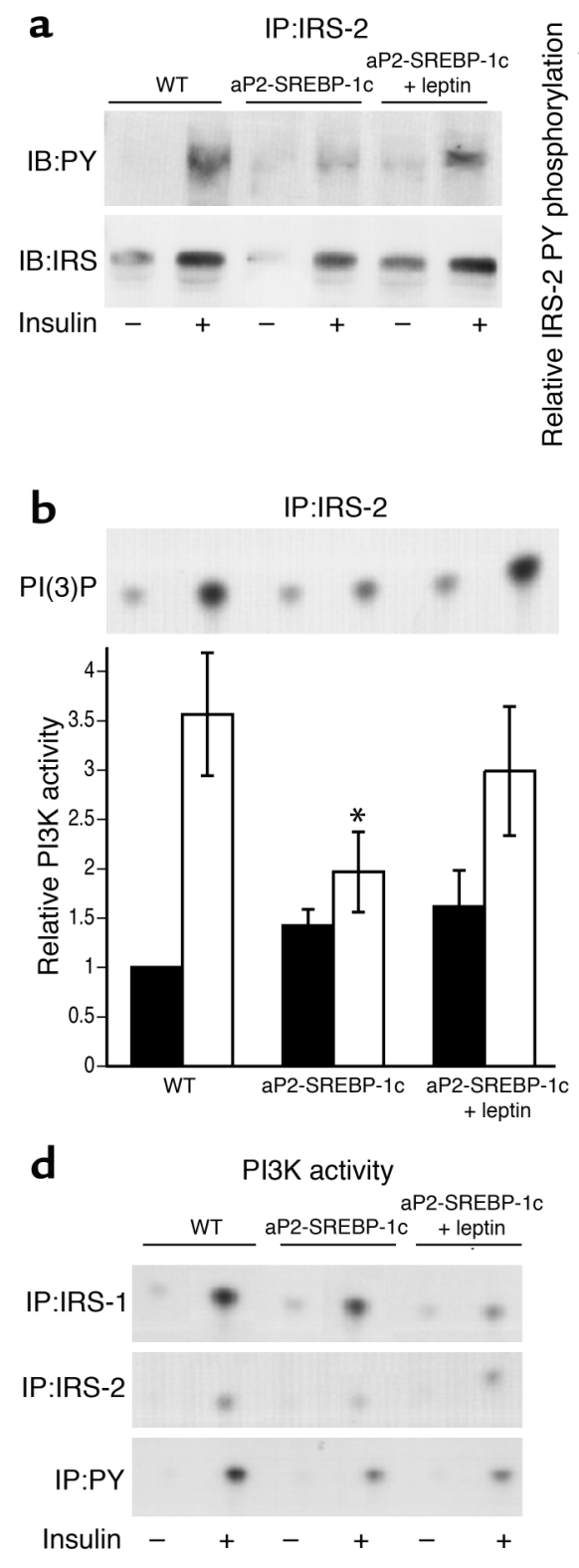

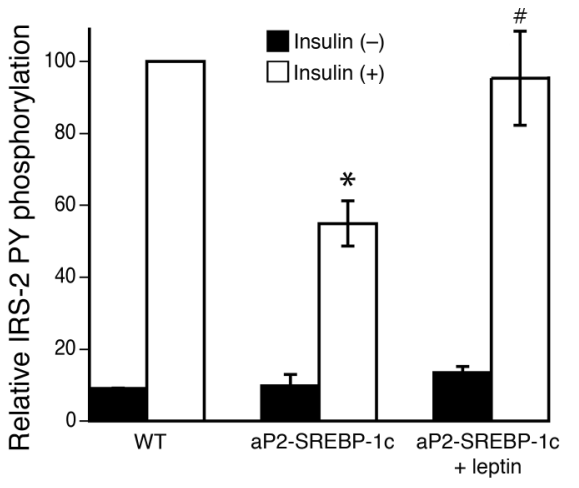

c p-Akt
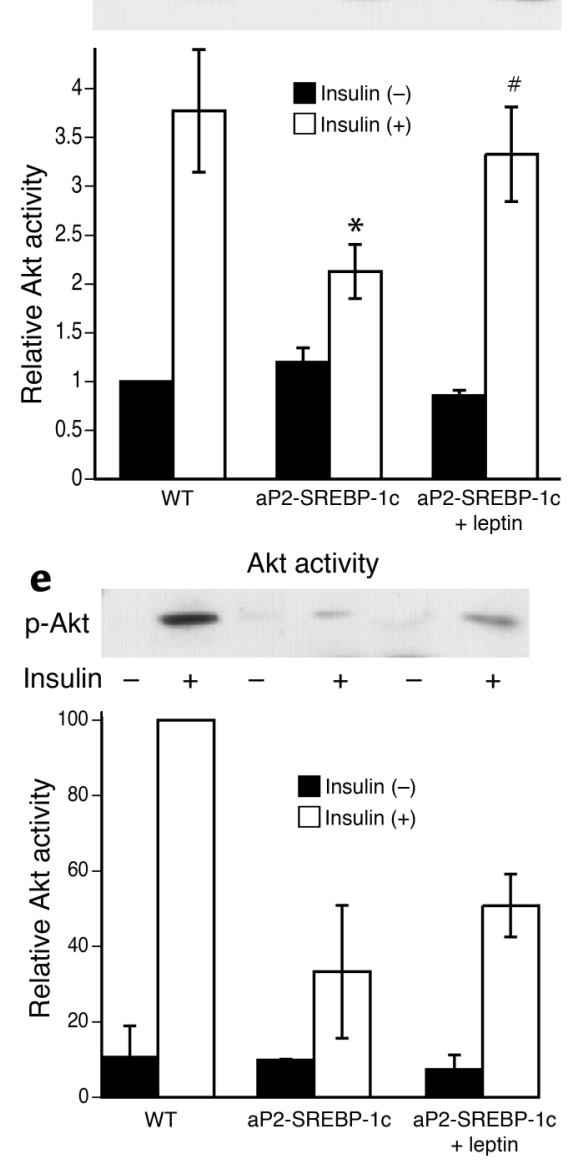

\section{Figure 7}

Insulin signal transduction after leptin treatment. Subcutaneous leptin leads to an improvement of insulin signaling in liver but not in muscle of aP2-SREBP-1c mice treated with $50 \mathrm{ng} / \mathrm{h}$ of subcutaneous leptin. (a) Insulin-induced tyrosine phosphorylation of IRS molecules in liver. (b) PI3K activities associated with tyrosine-phosphorylated proteins in liver. (c) In vitro AKT kinase activity in liver. The upper panels in $\mathbf{b}$ and $\mathbf{c}$ show representative results of relative immunoblot analysis, and in the lower panels, error bars indicate the SE; $n=4$. ${ }^{*} P<0.05$, WT vs. aP2-nSREBP-1c; ${ }^{\#} P<0.05$, aP2-nSREBP$1 c$ vs. aP2-nSREBP-1c plus leptin. (d) $\mathrm{PI} 3 \mathrm{~K}$ activities associated with tyrosinephosphorylated proteins in muscle. (e) In vitro AKT kinase activity in muscle. The upper panel shows representative results of immunoblot analysis, and in the lower panel, each bar represents the mean calculated from two independent experiments. IB, immunoblot; IP, immunoprecipitation; PY, phospho tyrosine; $\mathrm{PI}(3) \mathrm{P}$, $\mathrm{Pl}(3)$ phosphate.

Leptin could improve diabetes in lipodystrophy by an insulin-dependent or insulinindependent mechanism. The data presented here support the former possibility and suggest that leptin treatment improves insulin signal transduction in liver. Leptin enhances IRS-2 phosphorylation, IRS-2-associated PI3K activity, and Akt activity in livers of aP2nSREBP-1c mice. This insulinsensitizing effect in liver seems to be SCD independent, since leptin can improve hyperglycemia and hyperinsulinemia at doses that do not correct SCD-1 expression and enzymat-

finding that pair-feeding of aP2-nSREBP-1c transgenic mice significantly reduces liver triglycerides to near-normal levels, while the mice remain diabetic (9). Similarly, $o b / o b$ mice lacking PPAR $\gamma$ in the liver have a significant reduction in liver triglycerides while remaining hyperglycemic and insulin resistant (42). Thus, reduction of the liver triglyceride content of lipodystrophic mice might not by itself be sufficient to correct their diabetes. This possibility is also suggested by our observation that leptin can correct diabetes and improve hepatic insulin sensitivity in lipodystrophic animals at doses that do not correct hepatic steatosis to WT levels. ic activity to WT levels. This suggests that other leptinregulated genes or pathways are necessary for leptin's insulin-sensitizing effects. The observation that insulin action is improved at a dose of leptin as low as $50 \mathrm{ng} / \mathrm{h}$ may simplify further efforts to elucidate the biochemical mechanism, because potentially confounding effects of this hormone on triglyceride levels and perhaps lipid metabolism are not evident at this dose. Of note, the effects of chronic leptin on glucose metabolism reported here are somewhat different from the acute effects of leptin. In previous studies, leptin was shown to acutely stimulate glucose metabolism in WT mice by an insulin-independent mechanism and to 
acutely increase glucose turnover in $o b / o b$ mice $(5,43)$. The basis for this difference is unknown but could relate to the differential effects of this hormone on liver before and after glycogen stores are depleted.

Finally, we used a novel approach that quantifies the extent of similarity between two pairs of samples and computes the significance of the correlation to compare the effects of central and peripheral leptin. This analysis revealed a nearly identical set of effects of icv and subcutaneous leptin on liver gene expression. This type of analysis is potentially relevant in other settings, including clinical pathology, and for example could be used to determine the significance of the similarity of two tumor samples. The analyses of microarray data do suggest that peripheral leptin has distinct effects on gene expression in skeletal muscle compared with central leptin. While the data from the CNS leptin infusions suggest that these effects are not essential for leptin's effect, the physiologic relevance of these differences can be further investigated using mice with a musclespecific knockout of the leptin receptor $(15,44)$. These results showed that for the vast majority of leptin-regulated genes in liver, icv leptin is even more potent than a much higher dose of peripheral leptin. This includes the RNAs for several SREBP-1c-regulated genes, which are generally repressed by leptin. However, in this case we did not observe a change in the RNA levels of SREBP-1c itself. It is possible, however, that SREBP-1c is regulated at the post-transcriptional level and that, as previously shown in adipose tissue, leptin influences the amount of SREBP cleavage in liver (45).

In conclusion, our findings suggest that leptin's ability to improve the metabolic abnormalities of lipodystrophic mice is indirect via the CNS and that leptin's effect to reduce hepatic steatosis is mediated in part by repression of SCD-1. The current study directly relates to the mechanism of action of leptin in treating the metabolic syndrome associated with lipodystrophy and specifically elucidates the mechanism by which leptin improves hepatic steatosis, a major risk factor for the development of end-stage liver disease (46). While leptin also improves the diabetes associated with lipodystrophy, its antidiabetic effects appear to be independent of its ability to inhibit this enzyme, a possibility that merits further investigation. A fuller understanding of the mechanism underlying leptin's insulin-sensitizing effects may have important implications for the treatment of diabetes. These results also suggest that leptin treatment could improve insulin signaling in other settings. Even though lipodystrophy is a rare condition, many HIV patients who have been treated with highly active antiretroviral therapy have developed this disease, and leptin treatment may also prove to be of benefit for this growing medical problem.

\section{Acknowledgments}

We thank S. Wakil for supplying the highly purified fatty acid synthase for malonyl-CoA measurements; A. Viale from the Genomics Core Laboratory at Memori- al Sloan-Kettering Cancer Center for critical discussions on Affymetrix data analysis and for the processing of Affymetrix gene-chip arrays; A. Pithart for assistance with animal maintenance and surgeries; $Z$. Chen for providing TaqMan primers and probes; F. Quimby for assistance with histology; J. Montez for providing Affymetrix data; W. Liedtke, S. Novelli, S. Pinto, and B. Taneri for critical reading of the manuscript; and S. Korres for help in preparing the manuscript. This work was supported in part by NIH grant RO1-DK62388 (to J.M. Ntambi), Albert Einstein College of Medicine and the Seaver Foundation Center for Bioinformatics (N.D. Socci), NIH grant MSTP GM07739 (to P. Cohen), and NIH grant R01-DK41096 (to J.M. Friedman).

1. Zhang, Y., et al. 1994. Positional cloning of the mouse obese gene and its human homologue. Nature. 372:425-432.

2. Friedman, J.M. 2000. Obesity in the new millennium. Nature. 404:632-634.

3. Chinookoswong, N., Wang, J.L., and Shi, Z.Q. 1999. Leptin restores euglycemia and normalizes glucose turnover in insulin-deficient diabetes in the rat. Diabetes. 48:1487-1492.

4. Ogawa, Y., et al. 1999. Increased glucose metabolism and insulin sensitivity in transgenic skinny mice overexpressing leptin. Diabetes. 48:1822-1829.

5. Kamohara, S., Burcelin, R., Halaas, J.L., Friedman, J.M., and Charron, M.J. 1997. Acute stimulation of glucose metabolism in mice by leptin treatment. Nature. 389:374-377.

6. Oral, E.A., et al. 2002. Leptin-replacement therapy for lipodystrophy. N. Engl.J. Med. 346:570-578.

7. Petersen, K.F., et al. 2002. Leptin reverses insulin resistance and hepatic steatosis in patients with severe lipodystrophy. J. Clin. Invest. 109:1345-1350. doi:10.1172/JCI200215001.

8. Shimomura, I., et al. 1998. Insulin resistance and diabetes mellitus in transgenic mice expressing nuclear SREBP-1c in adipose tissue: model for congenital generalized lipodystrophy. Genes Dev. 12:3182-3194.

9. Shimomura, I., Hammer, R.E., Ikemoto, S., Brown, M.S., and Goldstein, J.L. 1999. Leptin reverses insulin resistance and diabetes mellitus in mice with congenital lipodystrophy. Nature. 401:73-76.

10. Moitra, J., et al. 1998. Life without white fat: a transgenic mouse. Genes Dev 12:3168-3181.

11. Ebihara, K., et al. 2001. Transgenic overexpression of leptin rescues insulin resistance and diabetes in a mouse model of lipoatrophic diabetes. Diabetes. 50:1440-1448.

12. Gavrilova, O., et al. 2000. Surgical implantation of adipose tissue reverses diabetes in lipoatrophic mice. J. Clin. Invest. 105:271-278.

13. Colombo, C., et al. 2002. Transplantation of adipose tissue lacking leptin is unable to reverse the metabolic abnormalities associated with lipoatrophy. Diabetes. 51:2727-2733.

14. Laustsen, P.G., et al. 2002. Lipoatrophic diabetes in Irs1(-/-)/Irs3(-/-) double knockout mice. Genes Dev. 16:3213-3222.

15. Cohen, P., et al. 2001. Selective deletion of leptin receptor in neurons leads to obesity. J. Clin. Invest. 108:1113-1121. doi:10.1172/JCI200113914.

16. Minokoshi, Y., et al. 2002. Leptin stimulates fatty-acid oxidation by activating AMP-activated protein kinase. Nature. 415:339-343.

17. Atkinson, L.L., Fischer, M.A., and Lopaschuk, G.D. 2002. Leptin activates cardiac fatty acid oxidation independent of changes in the AMP-activated protein kinase-acetyl-CoA carboxylase-malonyl-CoA axis. J. Biol. Chem. 277:29424-29430.

18. Kieffer, T.J., Heller, R.S., Leech, C.A., Holz, G.G., and Habener, J.F. 1997. Leptin suppression of insulin secretion by the activation of ATP-sensitive $\mathrm{K}+$ channels in pancreatic beta-cells. Diabetes. 46:1087-1093.

19. Cohen, P., et al. 2002. Role for stearoyl-CoA desaturase-1 in leptin-mediated weight loss. Science. 297:240-243.

20. Halaas, J.L., et al. 1997. Physiological response to long-term peripheral and central leptin infusion in lean and obese mice. Proc. Natl. Acad. Sci. U. S. A. 94:8878-8883.

21. Bligh, E.G., and Dyer, W.J. 1959. A rapid method of total lipid extraction and purification. Can.J. Biochem. Physiol. 37:911-917.

22. Miyazaki, M., Kim, H.J., Man, W.C., and Ntambi, J.M. 2001. Oleoyl-CoA is the major de novo product of stearoyl-CoA desaturase 1 gene isoform and substrate for the biosynthesis of the Harderian gland 1-alkyl-2,3-diacylglycerol. J. Biol. Chem. 276:39455-39461.

23. Kudo, N., Barr, A.J., Barr, R.L., Desai, S., and Lopaschuk, G.D. 1995. High rates of fatty acid oxidation during perfusion of ischemic hearts are associated with a decrease in malonyl-CoA levels due to an increase in $5^{\prime}$-AMPactivated protein kinase inhibition of acetyl CoA carboxylase. J. Biol. Chem. 270:17513-17520. 
24. Witters, L.A., and Kemp, B.E. 1992. Insulin activation of acetyl-CoA carboxylase accompanied by inhibition of the $5^{\prime}$-AMP-activated protein kinase. J. Biol. Chem. 267:2864-2867.

25. McGarry, J.D., Stark, M.J., and Foster, D.W. 1978. Hepatic malonyl-CoA levels of fed, fasted and diabetic rats as measured using a simple radioisotopic assay. J. Biol. Chem. 253:8291-8293.

26. Ueki, K., et al. 2002. Increased insulin sensitivity in mice lacking p85beta subunit of phosphoinositide 3-kinase. Proc. Natl. Acad. Sci. U. S. A. 99:419-424.

27. Shimomura, I., et al. 2000. Decreased IRS-2 and increased SREBP-1c lead to mixed insulin resistance and sensitivity in livers of lipodystrophic and ob/ob mice. Mol. Cell. 6:77-86.

28. Ntambi, J.M., et al. 1988. Differentiation-induced gene expression in 3T3L1 preadipocytes. Characterization of a differentially expressed gene encoding stearoyl-CoA desaturase. J. Biol. Chem. 263:17291-17300.

29. Ntambi, J.M. 1999. Regulation of stearoyl-CoA desaturase by polyunsaturated fatty acids and cholesterol. J. Lipid Res. 40:1549-1558.

30. Listenberger, L.L., et al. 2003. Triglyceride accumulation protects against fatty acid-induced lipotoxicity. Proc. Natl. Acad. Sci.U. S. A. 100:3077-3082.

31. Halaas, J.L., et al. 1995. Weight-reducing effects of the plasma protein encoded by the obese gene. Science. 269:543-546.

32. Miles, P.D., Yamatani, K., Lickley, H.L., and Vranic, M. 1991. Mechanism of glucoregulatory responses to stress and their deficiency in diabetes. Proc. Natl. Acad. Sci. U. S. A. 88:1296-1300.

33. Lee, Y., et al. 2002 PPAR alpha is necessary for the lipopenic action of hyperleptinemia on white adipose and liver tissue. Proc. Natl. Acad. Sci. U.S. A. 99:11848-11853.

34. Ntambi, J.M., et al. 2002. Loss of stearoyl-CoA desaturase-1 function protects mice against adiposity. Proc. Natl. Acad. Sci. U. S. A. 99:11482-11486

35. Volpe, J.J., and Vagelos, P.R. 1976. Mechanisms and regulation of biosynthesis of saturated fatty acids. Physiol. Rev. 56:339-417.

36. Lunzer, M.A., Manning, J.A., and Ockner, R.K. 1977. Inhibition of rat liver acetyl coenzyme A carboxylase by long chain acyl coenzyme A and fatty acid. Modulation by fatty acid-binding protein. J. Biol. Chem. 252:5483-5487.

37. McGarry, J.D., Mannaerts, G.P., and Foster, D.W. 1977. A possible role for malonyl-CoA in the regulation of hepatic fatty acid oxidation and ketogenesis. J. Clin. Invest. 60:265-270.

38. Zarjevski, N., Cusin, I., Vettor, R., Rohner-Jeanrenaud, F., and Jeanrenaud, B. 1993. Chronic intracerebroventricular neuropeptide-Y administration to normal rats mimics hormonal and metabolic changes of obesity. Endocrinology. 133:1753-1758.

39. Segal-Lieberman, G., et al. 2003. Melanin-concentrating hormone is a critical mediator of the leptin-deficient phenotype. Proc. Natl. Acad. Sci. U. S. A 100:10085-10090.

40. Lin, J., et al. 2003. CNS melanocortin and leptin effects on stearoyl-CoA desaturase-1 and resistin expression. Biochem. Biophys. Res. Commun. 311:324-328.

41. Shulman, G.I. 2000. Cellular mechanisms of insulin resistance. J. Clin Invest. 106:171-176

42. Matsusue, K., et al. 2003. Liver-specific disruption of PPAR $\gamma$ in leptin-deficient mice improves fatty liver but aggravates diabetic phenotypes. J. Clin. Invest. 111:737-747. doi:10.1172/JCI200317223.

43. Burcelin, R., et al. 1999. Acute intravenous leptin infusion increases glucose turnover but not skeletal muscle glucose uptake in ob/ob mice. Diabetes. 48:1264-1269.

44. Bruning, J.C., et al. 1998. A muscle-specific insulin receptor knockout exhibits features of the metabolic syndrome of NIDDM without altering glucose tolerance. Mol. Cell. 2:559-569.

45. Soukas, A., Cohen, P., Socci, N.D., and Friedman, J.M. 2000. Leptin-specific patterns of gene expression in white adipose tissue. Genes Dev. 14:963-980

46. Angulo, P. 2002. Nonalcoholic fatty liver disease. N. Engl. J. Med. 346:1221-1231. 